\title{
Uma conversação com Ruth Amossy
}

\author{
AlejandraVitale ${ }^{1}$ \\ Ruth Amossy²
}

\begin{abstract}
AV: Do seu ponto de vista, qual o diálogo disciplinar entre a Retórica e a Análise do discurso?
\end{abstract}

RA: Sabe-se que, por muito tempo, a Análise do Discurso e a argumentação retórica formaram uma combinação perigosa. Essa foi, sobretudo, a realidade dos anos 1970 e 1980, quando eclodiu a primeira escola de Análise do Discurso de linha francesa, inspirada em Foucault e Althusser e marcada pelos trabalhos de Michel Pêcheux. A concepção de sujeito que prevalecia na época se contrapunha à ideia de um sujeito plenamente senhor de si e das significações. A retórica clássica se apoiava na agência - a ação controlada de um locutor que maneja a arte da linguagem e intervém deliberadamente no real exercendo sua influência sobre o outro. Essa noção torna-se obsoleta e é desmistificada pelas teorias marxistas, psicanalíticas, estruturalistas e outras. Isso explica por que os trabalhos de Chaim Perelman, entre os quais a Nova Retórica (no tratado redigido com Lucie Olbrechts-Tyteca), que data de 1958, tenham sido negligenciados por tanto tempo.

Quando comecei a trabalhar com a argumentação retórica enquanto quadro comunicacional, no qual se efetua uma troca visando a adesão do alocutário a uma tese ou visão, já no começo senti falta de uma abordagem linguística apropriada. Perelman era filósofo e tinha mobilizado em seu trabalho elementos de gramática tradicional, cujo uso certamente foi o melhor possível para sua reflexão, mas que não possibilitavam depreender os funcionamentos discursivos em contexto e esclarecer os mecanismos verbais da persuasão. Por isso me voltei para a pragmática, que tomava a linguagem como ação, e para a $\mathrm{AD}$, que estudava não a língua como um sistema, mas o discurso em situação. Estava, então, comprovado que a retórica e as ciências da linguagem contemporâneas eram complementares para compreender a forma como os sujeitos falantes procuram se influenciar mutualmente e constroem através da sua fala uma visão do real e uma concepção do que convém decidir e realizar. Aliás, essa era a direção proposta por Christian Plantin, que cruza retórica (inspirada principalmente em Perelman) e análise das interações verbais. Foi o que eu mesma busquei teorizar, embora mais a partir do discurso do que de interações face a face, na primeira versão da minha obra L'argumentation dans le discours (2000), cujo sucesso, a meu ver, deve-se em grande parte à integração em um só conjunto coerente das duas abordagens, até então consideradas distintas ou mesmo incompatíveis.

Sem dúvida, nesse âmbito se reconhece que o poder do verbo é limitado por diversas imposições, contempladas pela retórica à sua maneira. Apontemos, em particular, os gêneros de discurso, em toda sua variedade e complexidade, (além dos gêneros retóricos); ou, ainda, a doxa tomada tanto como o saber do senso comum que conduz a linguagem e que

1 Universidad de Buenos Aires.

2 Ruth Amossy é profesora emérita da Universidade de Tel Aviv, onde coordena o grupo de pesquisa ADARR (Análise do Discurso, Argumentação, Retórica). Especialista em literatura e cultura francesas dos séc. XIX e XXI e em Análise do Discurso e Retórica. Publica inúmeros estudos sobre o clichê e o estereótipo e tem investigado, particularmente, as noções de ethos e de polêmica. 
molda o discurso, independentemente dos sujeitos falantes, quanto como o lugar comum no qual eles podem se encontrar e se identificar. Assim, a fala é concebida ao mesmo tempo como parcialmente determinada pelo discurso social da época e suas evidências, e como um instrumento de ação e de poder. Essa última vertente torna possível a agência retórica que oferece ao indivíduo suas capacidades de intervenção e faz dele um sujeito responsável. Essa relação entre a argumentação retórica e análise do discurso aos poucos se estabilizou e se institucionalizou e hoje a encontramos em construções teóricas variadas.

Vale acrescentar que esse diálogo entre disciplinas foi especialmente frutífero no que diz respeito aos trabalhos desenvolvidos a partir de algumas noções emprestadas da retórica, tais como o ethos e o pathos. Foram realizados trabalhos de qualidade sobre a construção das emoções no discurso e sobre a construção discursiva do ethos, introduzida na $\mathrm{AD}$ a princípio por Dominique Maingueneau.

AV: Quais são, de acordo com sua perspectiva, as abordagens epistemológicas sobre a argumentação no discurso e como você pode descrevê-las?

RA: Se retomo algo das premissas que fundamentam minha teoria da argumentação no discurso, poderia insistir sobre os seguintes pontos.

Ela confere ao discurso o poder de construir o real. Longe de ver na linguagem o reflexo de uma realidade pré-existente e a expressão de uma identidade pré-formada, essa abordagem reúne todas aquelas que, nas ciências humanas e sociais, insistem sobre o fato de que a identidade, as relações humanas, o acontecimento, etc... se constroem na utilização da linguagem e na troca verbal.

É assim acordada à interação verbal uma importância primordial (seja ela atual ou virtual) e a possibilidade que ela ofereçe de fazer significar o mundo e de chegar a um acordo ou de explorar uma dissenssão, por meio do diálogo e do polilogos.

De modo similar, a ênfase é colocada sobre o dialogismo vertical, o que faz, conforme Bakhtin, que toda palavra seja uma resposta à palavra do outro, considerando que o enunciado novo não seja gerado e nem adquira sentido senão em uma circulação generalizada de discursos. Isto coloca-nos diante das noções de intersubjetividade (Benveniste), interdiscursividade (AD) e de discurso social (Angenot).

Também retoma a noção de doxa que está no centro do pensamento retórico, não como banalidade a condenar (o sentido moderno), mas como o conjunto de crenças, de opiniões e de representações que partilham os membros de um grupo em um dado momento.

É fundando-se sobre estas premissas comuns que os indivíduos podem trocar, discutir, negociar suas posições, polemizar. Desde modo, a doxa não é o espaço alienante das ideias recebidas que impede de pensar, mas o lugar comum no qual os homens encontram-se para negociar suas visões. Não se pode esquecer ainda que esta doxa (que não é necessariamente uma, em uma dada sociedade e pode diferenciar-se em correntes diversas) é feita de palavras e não pode existir fora de sua materialidade linguageira.

É sobre este fundo que se inscreve o ideal da argumentação retórica que permite ultrapassar os pesos deterministas promovendo um certo grau de agentividade: ela confere ao locutor o poder de agir sobre o real, influindo sobre o outro, responsabilizando-o e encontrando no uso da palavra uma possibilidade de modificar seu estatuto (por exemplo, autorizando o que a língua inglesa denomina "empoderamento").

Com efeito, em uma sociedade democrática é importante que as decisões posam ser tomadas em comum - é o que permite o logos como palavra e como razão, ou seja, a mu- 
dança de argumentos. Esta vocação da retórica é levada adiante pelos trabalhos de Chaim Perelman, os quais centram-se sobre a importância de um discurso dirigido ao outro, o qual busca não a verdade, mas o razoável e o plausível. É importante também levar em conta o fato de que as dissensões podem ter um curso livre - considerando-se que os conflitos são inevitáveis na democracia - dentro de um conjunto vivo que designei como a coexistência no dissenso. Dentro deste quadro global o sujeito falante (locutor individual ou grupo) pode fazer uso da linguagem como logos, mas também como pathos e projetar uma imagem de si apropriada (o ethos) para intervir no espaço social e político.

É em torno de tais fundamentos que o meu trabalho dá relevo a uma teoria da argumentação no discurso que integra, dentro de um quadro coerente, duas disciplinas que à primeira vista pareceriam se excluir.

AV: No momento, qual pesquisa você está desenvolvendo ou qual tema você tem estudado?

RA: Nos últimos anos, trabalhei com a utilização retórica do que Alice Krieg-Planque chamou de "fórmula" e que se inscreve na linha de meus trabalhos anteriores sobre o clichê e o estereótipo. Em particular, analisei as modalidades de utilização, na mídia francesa, de uma fórmula vinda de Israel e retomada por seus defensores franceses e francófonos: "a deslegitimação de Israel". Essa expressão fixa tem como objetivo fazer face aos ataques virulentos lançados contra o Estado Judeu em praça pública, denunciando o caráter sensacionalista e falso de tais manifestações - de certa forma, Israel se torna o "Judeu das nações". A maneira como essa fórmula é colocada em circulação no discurso midiático evidencia a guerra de palavras que opõe os pró-israelitas aos pró-palestinos, no contexto de um país em que o conflito no Oriente Médio é objeto de um debate particularmente difícil. Esse estudo combina os instrumentos da AD e da argumentação retórica para mostrar a construção de um diálogo argumentativo que envolve a guerra de legitimidades, e a lógica que sustenta uma polêmica que os eventos no Oriente Médio continuam levantando.

Além disso, atualmente desenvolvo um estudo sobre a reparação da imagem das mulheres e homens da política; o discurso das eleições presidenciais, baseando-me em trabalhos realizados sobre o tema na área das ciências da comunicação (por William Benoit) e nas abordagens do ethos, do ethos prévio e do ethos coletivo, desenvolvidas na AD e na Argumentação Retórica.

Tradução: Maitê Dietze, Ana Zandwais. Revisão: Patrícia Reuillard (UFRGS).

\section{Traduções para Espanhol:}

AMOSSY, R. La interacción argumentativa en el discurso literario. De la literatura de las ideas al relato de fición. Escritos, La argumentaçion. Puebla: BUAP - (Benemerita Universidad Autonoma de Puebla), 1998, p. 249-289.

. ; PIERROT, A. Estereotipos y clichés. Buenos Aires: Eudeba, Universidad de Buenos Aires, 2001. Trad. y adaptación: Lelia Gándara.

. Argumentación y análisis del discurso: perspectivas teóricas y recortes disciplinarios. El discurso y sus espejos. México: Universidad Nacional Autónoma de México, 2009, p. 67-97. 


\section{Conexão Letras}

. Argumentación y Análisis del discurso perspectivas teóricas y límites disciplinares. Estudios y Análisis del Discurs, Cuadernos de Lingüística, n. 1, v. 3, 2009, p. 173190.

. La indignación frente a la "stock-options" de la Société Générale. Emoción y argumentació en el discurso polemico. Version 24, 2010, p. 17-40.

. Estereotipos e identidad. La construcción del ethos. En: LIE, N.; MANDOLESSI, S.; VANDEBOSCH, D. (Éd). El juego con los estereotipos. La redefinición de la identidad hispánica en el cine y la literatura postnacionales. Bern/Berlin: Peter Lang, 2011, p. 27-44.

. Por una retórica del dissensus: las funciones de la polémica. En: MONTERO, A. (Comp. y Trad.). El análisis del discurso polémico. Disputas, querellas y controversias. Buenos Aires: Prometeo, 2016, p. 25-38.

Recebido em: 26/10/2017 Aceito em: 10/11/2017 